\title{
MULTI-RESPONSE OPTIMIZATION OF LASER CUTTING Parameters using Grey Relational ANAlysis
}

\author{
Derzija Begic-Hajdarevic, Mirko Ficko, Ahmet Cekic, \\ Simon Klancnik \& Maida Cohodar
}
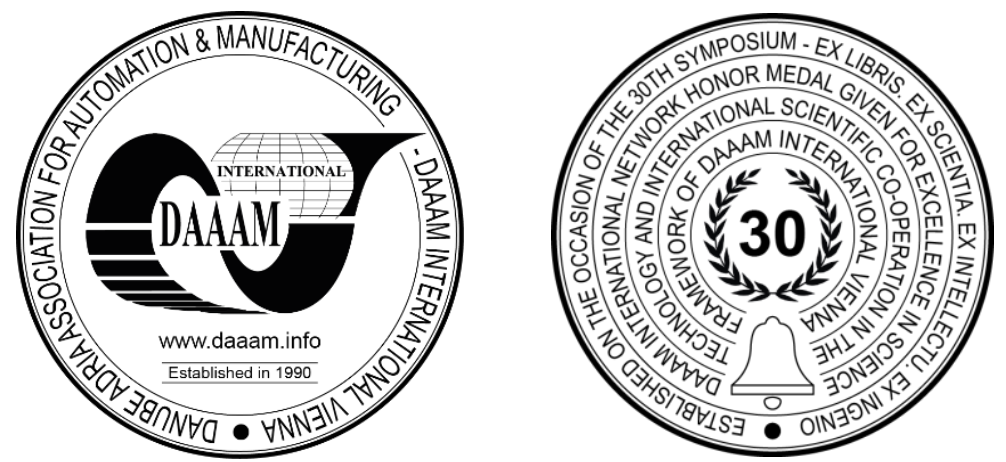

This Publication has to be referred as: Begic-Hajdarevic, D[erzija]; Ficko, M[irko]; Cekic, A[hmet]; Simon, K[lancnik] \& Cohodar, M[aida] (2019). Multi-response Optimization of Laser Cutting Parameters Using Grey Relational Analysis, Proceedings of the 30th DAAAM International Symposium, pp.0176-0183, B. Katalinic (Ed.), Published by DAAAM International, ISBN 978-3-902734-22-8, ISSN 1726-9679, Vienna, Austria DOI: $10.2507 / 30$ th.daaam.proceedings.023

\begin{abstract}
This paper presents an approach for the optimization of laser cutting process of aluminium alloy with multi-response outputs based on the Grey relational analysis (GRA). For experimental design, tests are planned based on Taguchi's L9 orthogonal array. The laser cutting parameters such as laser power and cutting speed are optimized with consideration of multi-response outputs such as top kerf width and surface roughness. It is observed that the laser power has stronger effect on multi-response outputs than cutting speed. According to multi-response optimization results, which are obtained from the highest value of the grey relational grade (GRG), the optimum combination is $2500 \mathrm{~W}$ laser power and $2.4 \mathrm{~m} / \mathrm{min}$ cutting speed to simultaneously minimize the kerf width and surface roughness.
\end{abstract}

Keywords: Laser cutting; optimization; Grey relational analysis; aluminium alloy.

\section{Introduction}

Laser cutting process a thermal energy-based non-conventional sheet metal cutting method in which sheet material is cut due to melting by thermal energy and ejecting molten material with the help of high-pressure assist gas jet [1]. Asist gas is supplied through a nozzle with pressure to remove the molten material. Laser cutting is one of the important applications of lasers in industry, especially for machining the difficult to cut materials. This cutting process has special advantages over other known thermal processes due to the high quality and very smooth cut surface, narrow kerf width, small heat affected zone, small metal deformation, perpendicular and sharp cut sides, square corners of cut edges and little or no oxide layer [2]. To maintain a high production rate and to achieve acceptable level of quality characteristics, it is important to choose optimum combination of input process parameters. Usually these parameters are cutting speed, laser power, focus position, the pressure and type of assist gas, and pulse frequency. Ghany and Newishy [3] studied the influence of machining parameters such as cutting speed, laser power, pulse frequency and focal position on the cut quality for $1.2 \mathrm{~mm}$ austenitic stainless steel by using pulsed and continuous wave Nd:YAG laser. It is shown that nitrogen produced brighter and smoother cut surfaces with smaller kerf instead of oxygen. $\mathrm{CO}_{2}$ laser cutting of stainless steel of medical grade AISI316L using nitrogen as an assist gas is analysed in [4]. Results are shown that the upper kerf width 
increases as the laser power, pressure of nitrogen and diameter of nozzle increase, but it decreases by increasing of cutting speed and focus position. The parametric analysis of process parameters for fiber laser cutting system on quality characteristics in the cutting of $3 \mathrm{~mm}$ stainless steel sheet is done [5]. It is observed that the laser power had more effect on responses rather than cutting speed and gas pressure.

For modelling and optimization of any machining processes, numerical method [6] and [7], artificial neural network [8] and [9], fuzzy logical method [10], regression analysis [11] and [12], and other intelligent techniques [13] and [14] are common used. The Grey system theory was first proposed by Deng [15] and also this theory has been applied to the different fields of machining process. Grey relational analysis is used [16] to determine optimal machining parameters during wire electrical discharge machining (WEDM) process of $\mathrm{Al}_{2} \mathrm{O}_{3}$ particle reinforced material with multipleperformance characteristics, such as the surface removal rate and the maximum surface roughness. Sarikaya and Gullu [17] optimized the turning parameters such as cutting fluid, fluid flow rate and cutting speed based on the multiperformance characteristics including flank wear, notch wear and surface roughness using Taguchi-based grey relational analysis. An orthogonal array is used for experimentation and grey relational analysis method is then applied to determine optimal machining parameters in plasma arc cutting process of stainless steel [18]. Grey relational analysis is used [19] for optimizing the drilling process parameters such as feed rate, cutting speed, drill type and point angles of drill with multi-performance characteristics such as the surface roughness and the burr height. Caydas and Hascalik [20] applied Taguchi method and grey relational analysis to optimize laser cutting parameters such as laser power and cutting speed with consideration of multiple-performance characteristics such as surface roughness, top kerf width and width of heat affected zone in cutting of St-27 steel. Tamrin et al. [21] used grey relational analysis to determine a single optimized set of cutting parameters for precision laser cutting of three different thermoplastics.

From the review literature, it can be observed that the grey relational analysis has found wide application areas for obtaining the optimal process parameters to different fields of machining processes. The purpose of this study is to determine the optimal cutting parameters such as laser power and cutting speed with consideration of multi-response outputs such as top kerf width and surface roughness in laser cutting of $4 \mathrm{~mm}$ thick aluminium alloy AlMg3.

\section{Experimental procedure}

The experiments are carried out on a Trumpf $3030 \mathrm{CO}_{2}$ laser system with a nominal output power of $4000 \mathrm{~W}$ in $\mathrm{CW}$ mode at a wavelength of $10.6 \mu \mathrm{m}$. Aluminium alloy AlMg3 sheet with thickness of $4 \mathrm{~mm}$ is used as work piece material. The laser beam is focused using a $127 \mathrm{~mm}$ focal length lens. Nitrogen assist gas is used coaxially with the laser beam via a $1.7 \mathrm{~mm}$ exit diameter nozzle. Experimental studies are carried out at the constant assist gas pressure of 16 bar. Two input process parameters such as laser power and cutting speed have been selected for the present study. The numerical values of these parameters are shown in Table 1. Testing the influence of one parameter on the cut quality requires the variation of one parameter while keeping the other parameters at the pre-selected values.

\begin{tabular}{|c|c|c|c|c|c|}
\hline Symbol & Input Parameters & Unit & Level 1 & Level 2 & Level 3 \\
\hline A & Laser power & W & 2500 & 3600 & 4000 \\
\hline B & Cutting speed & $\mathrm{m} / \mathrm{min}$ & 0.5 & 1.4 & 2.4 \\
\hline
\end{tabular}

Table 1. Input process parameters and their levels used in the designed experiments

The experimental results after laser cutting are evaluated in terms of the following measured machining performances: top kerf width and surface roughness. A visual inspection of each cut is carried out to ensure that no pitting and burrs are present in the cut area. The sample geometry of the measurements taken are shown in Figure 1.

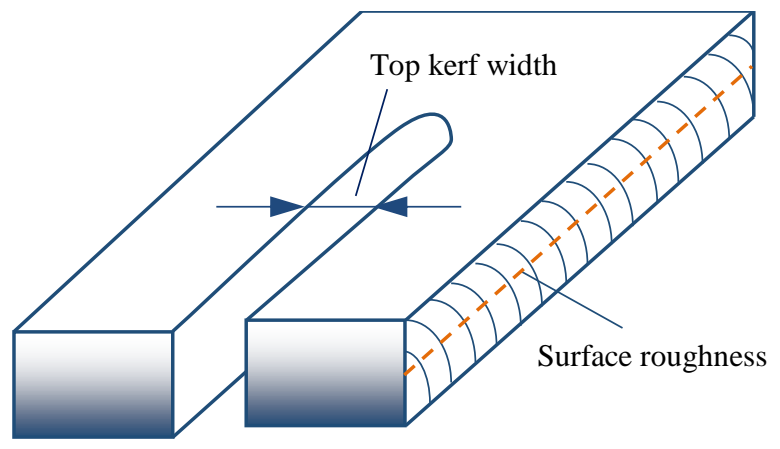

Fig. 1. Measurement of multi-performance responses 
Surface roughness on the laser cut edge is measured in terms of the average roughness $R_{a}$, using a Mitutoyo SJ-201 stylus instrument. The surface roughness is measured along the length of laser cut at approximately the middle of thickness. The kerf width is measured using a ZKM universal two-coordinate microscope.

Based on Taguchi's L 9 orthogonal array has been selected for performing the experiments. The experimental results are summarized in Table 2.

\begin{tabular}{|c|c|c|c|c|}
\hline $\begin{array}{c}\text { Experiment } \\
\text { No. }\end{array}$ & $\begin{array}{c}\text { A } \\
\text { Power }(\mathbf{W})\end{array}$ & $\begin{array}{c}\text { B } \\
\text { Cutting speed } \\
(\mathbf{m} / \mathbf{m i n})\end{array}$ & $\begin{array}{c}\text { Top kerf width } \\
(\mathbf{m m})\end{array}$ & $\begin{array}{c}\text { Surface roughness, } \\
\boldsymbol{R a}(\boldsymbol{\mu m})\end{array}$ \\
\hline 1. & 1 & 1 & 0.34 & 1.43 \\
\hline 2. & 1 & 2 & 0.22 & 2.15 \\
\hline 3. & 1 & 3 & 0.15 & 2.1 \\
\hline 4. & 2 & 1 & 0.37 & 1.8 \\
\hline 5. & 2 & 2 & 0.18 & 1.88 \\
\hline 6. & 2 & 3 & 0.26 & 2.6 \\
\hline 7. & 3 & 1 & 0.38 & 2.21 \\
\hline 8. & 3 & 2 & 0.23 & 2 \\
\hline 9. & 3 & 3 & 0.29 & 1.59 \\
\hline
\end{tabular}

Table 2. Experimental layout using an $\mathrm{L}_{9}$ orthogonal array and multi-response results

\section{Results and discussion}

\subsection{Evaluation of process parameters using 3D-surface plots on responses}

In laser cutting process of any material is very important to choosing optimal input process parameters to achieving acceptable level of quality characteristics. In this case, the effect of laser power and cutting speed on the kerf width and surface roughness are analysed.

The effect of laser power and cutting speed on the kerf width and the surface roughness during $\mathrm{CO}_{2}$ laser cutting of 4 $\mathrm{mm}$ thick aluminium alloy is illustrated in figures 2 and 3, respectively. In figure 2, it can be observed that the kerf width decreases with increasing cutting speed and decreasing laser power. Also it can be seen, that kerf width is slightly changed at the minimum cutting speed for all of three varied laser powers. But, in figure 3 can be seen that the surface roughness decreases with decreasing cutting speed except at the maximum laser power. Also it can be observed that the smallest value of surface roughness is obtained for the maximum laser power and cutting speed or for the minimum laser power and cutting speed.

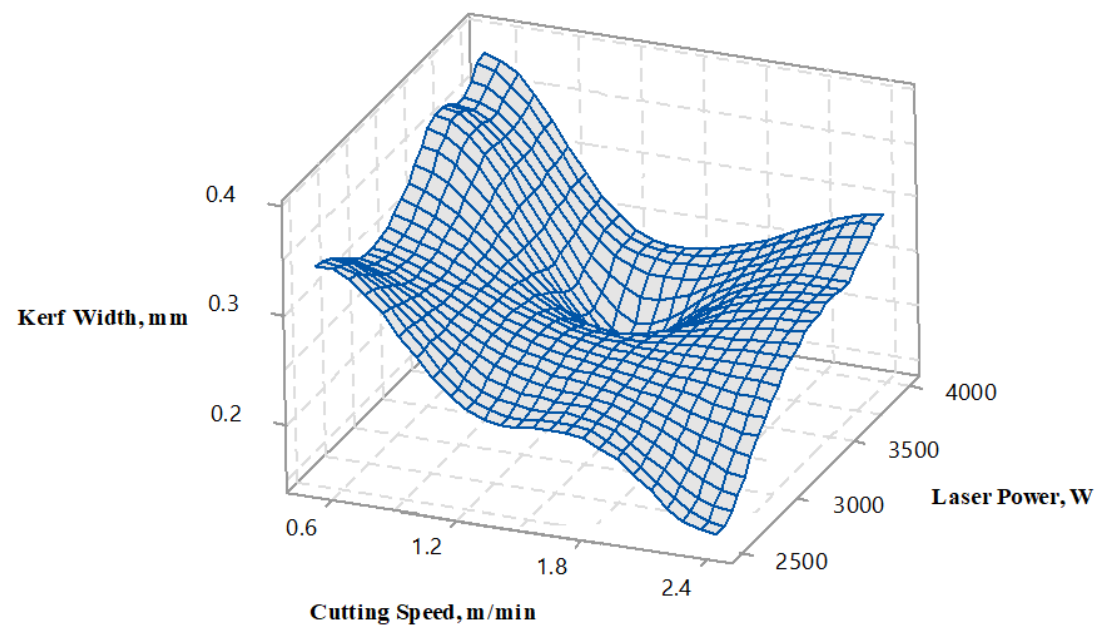

Fig. 2. 3D surface plots for effect of laser power and cutting speed on kerf width 


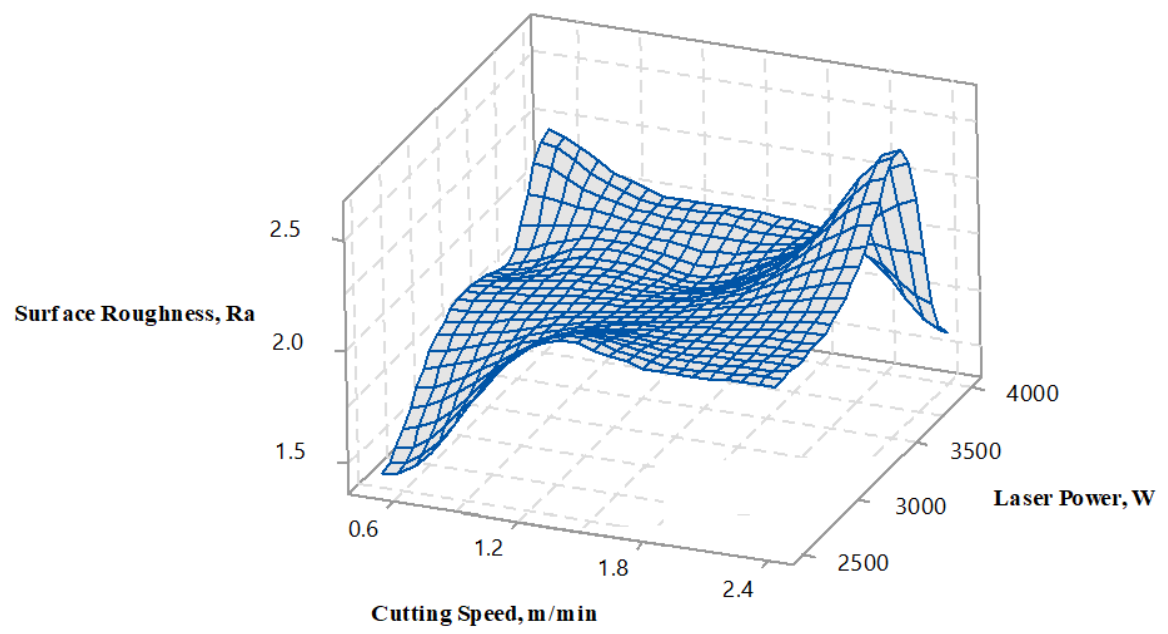

Fig. 3. 3D surface plots for effect of laser power and cutting speed on surface roughness

\subsection{Grey relational analysis}

Grey relational analysis is used for optimization multi-response characteristics. Optimization of such complicated characteristics can be converted into optimization single-response characteristic based on calculating Grey Relational Grade (GRG). In this case, there are two response characteristics that should be minimized. These are, the kerf width and surface roughness parameter $R a$.

Initial step in the grey relational analysis is normalization of the measured responses. Since the considered responses have to be minimized, the smaller-is-better approach is used for this study. This criterion can be expressed as:

$$
x_{i}(k)=\frac{\max y_{i}(k)-y_{i}(k)}{\max y_{i}(k)-\min y_{i}(k)}
$$

where, $y_{i}(k)$ is the $i$-th experimental result for the $k$-th process responses, $\max y_{i}(k)$ refers to the maximum value among $y_{i}(k)$, min $y_{i}(k)$ refers to the minimum value among $y_{i}(k)$, and $x_{i}(k)$ is the normalized value of $y_{i}(k)$.

The normalized values of kerf width and surface roughness is calculated by (1) are shown in Table 3 . After normalization, the deviation sequences are calculated by (2) and also are listed in Table 3.

$$
\Delta_{0 i}(k)=\left|x_{0}(k)-x_{i}(k)\right|
$$

where, $\Delta_{0 i}(k)$ is difference of the absolute value between $x_{0}(k)$ and $x_{i}(k)$, and $x_{0}(k)$ is the reference sequence of the $k$-th process response.

\begin{tabular}{|c|c|c|c|c|}
\hline \multirow{2}{*}{$\begin{array}{c}\text { Experiment } \\
\text { No. }\end{array}$} & \multicolumn{2}{|c|}{ Normalized values of responses } & \multicolumn{2}{c|}{ Deviation sequences, $\Delta_{\mathbf{0} \boldsymbol{i}}(\boldsymbol{k})$} \\
\cline { 2 - 5 } & Top kerf width & Surface roughness & Top kerf width & Surface roughness \\
\hline 1. & 0.1739 & 1.0000 & 0.8261 & 0.0000 \\
\hline 2. & 0.6957 & 0.3846 & 0.3043 & 0.6154 \\
\hline 3. & 1.0000 & 0.4274 & 0.0000 & 0.5726 \\
\hline 4. & 0.0435 & 0.6838 & 0.9565 & 0.3162 \\
\hline 5. & 0.8696 & 0.6154 & 0.1304 & 0.3846 \\
\hline 6. & 0.5217 & 0.0000 & 0.4783 & 1.0000 \\
\hline 7. & 0.0000 & 0.3333 & 1.0000 & 0.6667 \\
\hline 8. & 0.6522 & 0.5128 & 0.3478 & 0.4872 \\
\hline 9. & 0.3913 & 0.8632 & 0.6087 & 0.1368 \\
\hline
\end{tabular}

Table 3. Normalized values and deviation sequences of responses 
The next step in grey relational analysis is to determine the grey relational coefficient by using the equation:

$$
\xi_{i}(k)=\frac{\Delta_{\min }+\xi \cdot \Delta_{\max }}{\Delta_{0 i}(k)+\xi \cdot \Delta_{\max }}
$$

where, $\Delta_{\min }$ denotes smallest value of $\Delta_{0 i}(k), \Delta_{\max }$ denotes largest value of $\Delta_{0 i}(k)$, and $\xi$ is an identification coefficient. Its value can be chosen in the range of 0 to 1 . Generally, this coefficient has value of 0.5 .

The final step in grey relational analysis is to determine the grey relational grade (GRG) by averaging the sum of grey relational coefficients with the following equation:

$$
G R G_{i}=\frac{1}{n} \sum_{k=1}^{n} \xi_{i}(k)
$$

where, $\xi_{i}(k)$ is the grey relational coefficient of $k$-th process response in $i$ - th experiment and $n$ is the number of process responses.

\begin{tabular}{|c|c|c|c|c|}
\hline \multirow{2}{*}{$\begin{array}{c}\text { Experiment } \\
\text { No. }\end{array}$} & \multicolumn{2}{|c|}{ Grey relational coefficient, $\xi_{i}(k)$} & \multirow{2}{*}{$\begin{array}{l}\text { Grey relational grade, } \\
\qquad G R G_{i}\end{array}$} & \multirow{2}{*}{ Orders } \\
\hline & Top kerf width & Surface roughness & & \\
\hline 1. & 0.3770 & 1.0000 & 0.689 & 2 \\
\hline 2. & 0.6216 & 0.4483 & 0.535 & 6 \\
\hline 3. & 1.0000 & 0.4661 & 0.733 & 1 \\
\hline 4. & 0.3433 & 0.6126 & 0.478 & 7 \\
\hline 5. & 0.7931 & 0.5652 & 0.679 & 3 \\
\hline 6. & 0.5111 & 0.3333 & 0.422 & 8 \\
\hline 7. & 0.3333 & 0.4286 & 0.381 & 9 \\
\hline 8. & 0.5897 & 0.5065 & 0.548 & 5 \\
\hline 9. & 0.4510 & 0.7852 & 0.618 & 4 \\
\hline
\end{tabular}

The calculated values of grey relational coefficient and grey relational grade are given in Table 4 .

Table 4. The calculated grey relational coefficient and grey relational grade and its orders

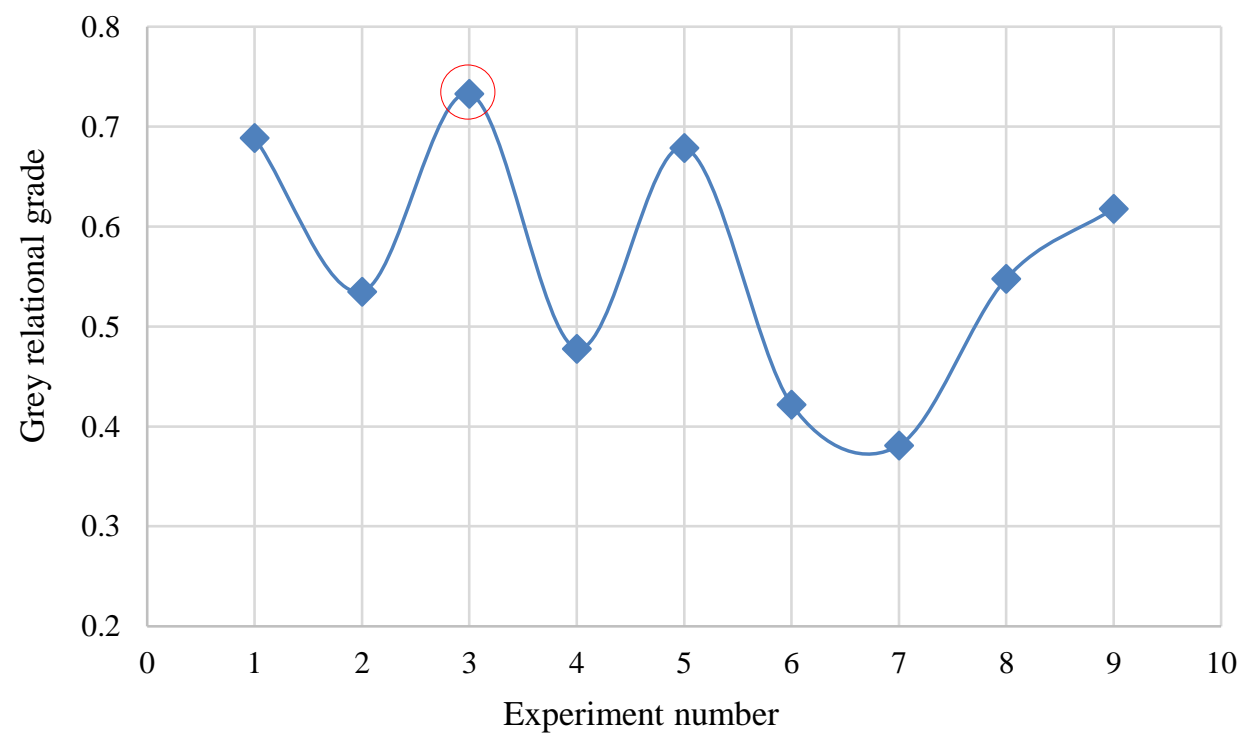

Fig. 4. Graph of grey relational grade

According to performed experiment design, it is clearly observed from Table 4 and figure 4 that the laser cutting parameters' setting of experiment no. 3 has the highest grey relational grade. Thus the experiment no. 3 gives the best multi-performance characteristics among the 9 experiments. 
Response table for the mean grey relational grade given in Table 5 shows that the optimum condition for highest grey relational grade i.e. $2500 \mathrm{~W}$ laser power and $2.4 \mathrm{~m} / \mathrm{min}$ cutting speed is marked in bold. The response graph for the cutting parameters of the laser cutting process is shown in figure 5. In this figure, the highest values give the low top kerf width and surface roughness and dashed line indicates the total average value of the grey relational grade.

\begin{tabular}{|c|c|c|c|c|c|c|}
\hline \multirow{2}{*}{ Symbol } & \multirow{2}{*}{ Parameters } & \multicolumn{6}{|c|}{ Grey relational grade } \\
\cline { 3 - 7 } & & Level 1 & Level 2 & Level 3 & Max-Min & Rank \\
\hline A & Laser power & $\mathbf{0 . 6 5 2}$ & 0.526 & 0.516 & 0.136 & 1 \\
\hline B & Cutting speed & 0.516 & 0.587 & $\mathbf{0 . 5 9 1}$ & 0.075 & 2 \\
\hline
\end{tabular}

Table 5. Response table for the mean grey relational grade

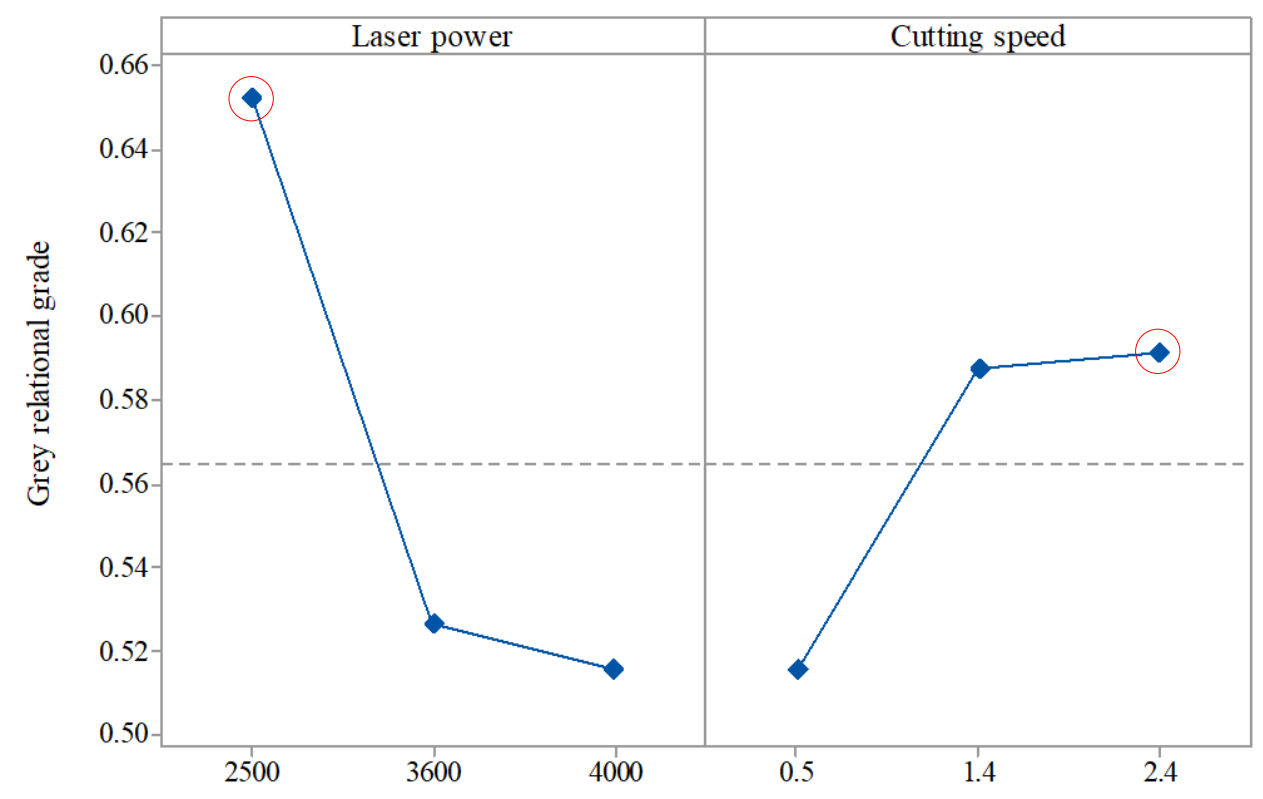

Fig. 5. Effect of laser cutting parameter on the grey relational grade

Also, it is observed that the difference between the maximum and minimum value of the grey relational grade for laser power is bigger than catting speed in Table 5. This indicates that the laser power has stronger effect on the multi-response outputs than cutting speed.

The difference between laser cut surface for the initial cutting conditions (experiment no. 1) and for the optimal cutting conditions (experiment no. 3) can be seen in Figure 6. Experiment no. 1 is ranked second among 9 experiments, but at this cutting conditions has occurred the dross.

a)

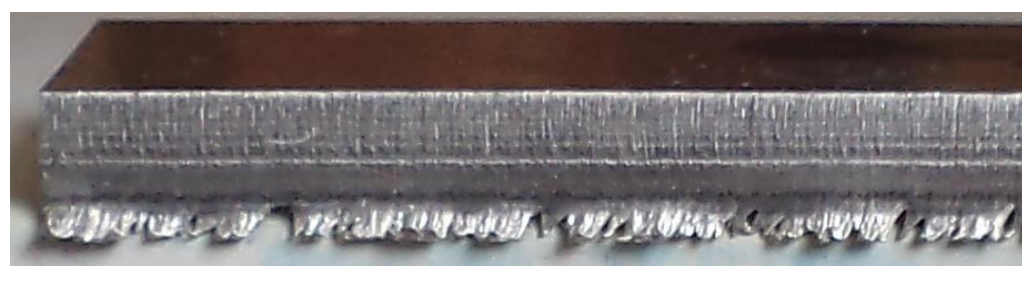

b)

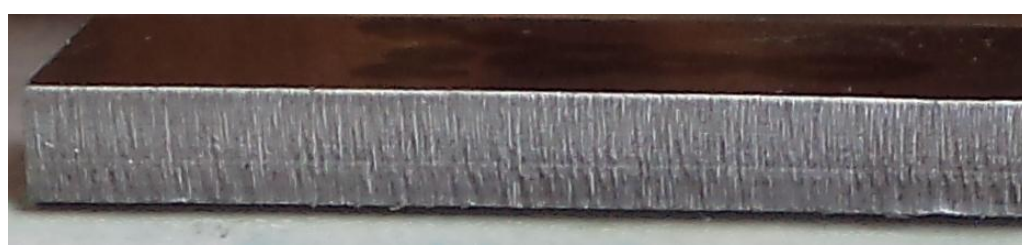

Fig. 6. Laser cut surface: (a) for initial cutting conditions; (b) for optimal cutting conditions 


\section{Conclusion}

This paper focused on the use of the Grey relational analysis to optimize the cutting parameters such as laser power and cutting speed with the multi-performance characteristics like top kerf width and surface roughness in laser cutting of $4 \mathrm{~mm}$ thick aluminium alloy. Results are shown that the laser power has stronger effect on multi-response outputs than cutting speed. According to multi-response optimization results, the optimum combination is $2500 \mathrm{~W}$ laser power and 2.4 $\mathrm{m} / \mathrm{min}$ cutting speed. It is shown that the performance characteristics of the laser cutting process such as kerf width and surface roughness are improved together by using grey relational analysis.

Future research would include analysis of additional factors that would effect on the cut quality characteristics as well as other types of material of different thickness.

\section{Acknowledgments}

The authors would like to thank the Ministry of Education, Science and Sport, Republic of Slovenia and the Federal Ministry of Education and Science, Bosnia and Herzegovina for their support of this study through the Bilateral Project entitled: "Intelligent monitoring of advanced machining processes - INTELUP19/20" and the Ministry of Education, Science and Youth of Sarajevo Canton.

\section{References}

[1] Dubey, AK. \& Yadava, V. (2008). Multi-objective optimization of laser beam cutting process. Optics \& Laser Technology, 40, pp. 562-570, ISSN: 0030-3992

[2] Avanish, K.D. \& Vinod, Y. (2008). Laser beam machining - A review. International Journal of Machine Tools \& Manufacture, 48, pp. 609-628, ISSN: 0890-6955

[3] Ghany, KA. \& Newishy, M. (2005). Cutting of $1.2 \mathrm{~mm}$ thick austenitic stainless steel sheet using pulsed and CW Nd:YAG laser. Journal of Materials Processing Technology, 168, pp.438-447, ISSN: 0924-0136

[4] Eltawahni, H.A.; Hagino, M.; Benyounis, K.Y.; Inoue, T. \& Olabi, A.G. (2012). Effect of $\mathrm{CO}_{2}$ laser cutting process parameters on edge quality and operating cost of AISI316L. Optics \& Laser Technology, 44, pp. 1068-1082, ISSN: 0030-3992

[5] Kotadiya, J. D.; Kapopara, M. J.; Patel, R. A.; Dalwadi, G. C. \& Pandya, H. D. (2018). Parametric analysis of process parameter for Laser cutting process on SS-304. Materials Today: Proceedings, 5, pp. 5384-5390, ISSN 2214-7853

[6] Begic-Hajdarevic, D. \& Bijelonja, I. (2014). Experimental and numerical investigation of temperature distribution and hole geometry during laser drilling process. Procedia Engineering, 100, pp.384-393, ISSN: 1877-7058

[7] Yan, Y.; Ji, L.; Bao, Y. \& Jiang. Y. (2012). An experimental and numerical study on laser percussion drilling of thick-section alumina. Journal of Materials Processing Technology, 212, pp.1257-1270, ISSN: 0924-0136

[8] Klancnik, S.; Begic-Hajdarevic, D.; Paulic, M.; Ficko, M.; Cekic, A. \& Cohodar Husic, M. (2015). Prediction of Laser Cut Quality for Tungsten Alloy Using the Neural Network Method. Strojniški vestnik - Journal of Mechanical Engineering, 61, 12, pp. 714-720, ISSN: 0039-2480

[9] Madic, M.J. \& Radovanovic, M.R. (2012). Analysis of the heat affected zone in $\mathrm{CO}_{2}$ laser cutting of stainless steel. Thermal Science, 16, pp. 363-373, ISSN: 2334-7163

[10] Saenz, C.D.; Castillo, G.N.; Romeva, C.R. \& Macia, L.J. (2015). A fuzzy approach for the selection of nontraditional sheet metal cutting processes. Expert Systems with Applications, 42, pp. 6147-6154, ISSN: 0957-4174

[11] Pasic, M.; Begic-Hajdarevic D. \& Bijelonja, I. (2018). Lase cut surface roughness modelling using regression analysis, Proceedings of the 29th DAAAM International Symposium, ISSN 1726-9679, ISBN 978-3-902734-20-4, Katalinic, B. (Ed.), pp. 0838-0845, DAAAM International, Vienna, DOI: 10.2507/29th.daaam.proceedings. 121

[12] Shrivastava, P.K. \& Pandey, A.K. (2018). Multi-Objective Optimization of Cutting Parameters during Laser Cutting of Titanium Alloy Sheet using Hybrid approach of Genetic Algorithm and Multiple Regression Analysis. Materials Today: Proceedings, 5, 11, pp. 24710-24719, ISSN: 2214-7853

[13] Ficko, M. \& Palcic, I. (2013). Designing a layout using the modified triangle method and genetic algorithms. International Journal of Simulation Modelling, 12, 4, pp. 237-251, ISSN: 1726-4529

[14] Klancnik, S.; Brezocnik, M. \& Balic, J. (2016). Intelligent CAD/CAM System for Programming of CNC Machine Tools. International Journal of Simulation Modelling, 15, 1, pp. 109-120, ISSN: 1726-4529

[15] Deng, J.L. (1989). Introduction to Grey system theory. The Journal of Grey System, 1, pp.1-24, ISSN: 0957-3720

[16] Chiang, K.T. \& Chang, F.P. (2006). Optimization of WEDM process of particle-reinforced material with multiple performance characteristics using grey relational analysis. Journal of Materials Processing Technology, 180 (1), pp.96-101, ISSN: 0924-0136

[17] Sarikaya, M. \& Gullu, A. (2015). Multi-response optimization of minimum quantity lubrication parameters using Taguchi-based grey relational analysis in turning of difficult-to-cut alloy Haynes 25. Journal of Cleaner Production, 91, pp.347-357, ISSN: 0959-6526

[18] Muhamedagic, K.; Begic-Hajdarevic, D.; Cekic, A. \& Mehmedovic, M. (2017). Multi-Response Optimization of Plasma Cutting Parameters using Grey Relational Analysis, Proceedings of the 28th DAAAM International 
Symposium, pp.1074-1082, B. Katalinic (Ed.), Published by DAAAM International, ISBN 978-3-902734-11-2, ISSN 1726-9679, Vienna, Austria, DOI: 10.2507/28th.daaam.proceedings.149

[19] Tosun, N. (2006). Determination of optimum parameters for multi-performance characteristics in drilling by using grey relational analysis. The International Journal of Advanced Manufacturing Technology, 28, 5-6, pp. 450-455, ISSN: 1433-3015

[20] Caydas, U. \& Hascalik, A. (2008). Use of the grey relational analysis to determine optimum laser cutting parameters with multi-performance characteristics. Optics \& Laser Technology, 40, pp. 987-994, ISSN: 0030-3992

[21] Tamrin, K.F.; Nukman, Y.; Choudhury, I.A. \& Shirley, S. (2015). Multiple-objective optimization in precision laser cutting of different thermoplastics. Optics and Lasers in Engineering, 67, pp. 57-65, ISSN: 0143-8166 